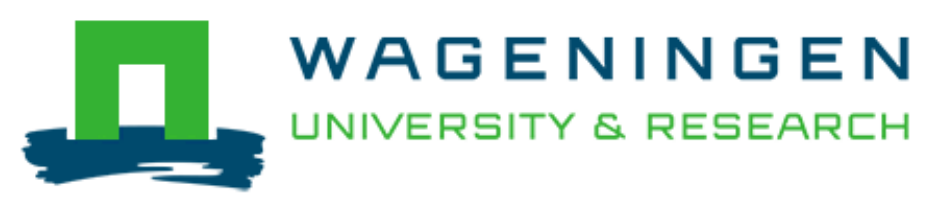

The influence of prey size, sediment thickness and fish size on consumption

in common sole (Solea solea L.)

Ende, S. S. W., Schrama, J. W., \& Verreth, J. A. J.

This article is made publically available in the institutional repository of Wageningen University and Research, under article $25 \mathrm{fa}$ of the Dutch Copyright Act, also known as the Amendment Taverne.

Article $25 \mathrm{fa}$ states that the author of a short scientific work funded either wholly or partially by Dutch public funds is entitled to make that work publicly available for no consideration following a reasonable period of time after the work was first published, provided that clear reference is made to the source of the first publication of the work.

For questions regarding the public availability of this article, please contact openscience.library@wur.nl.

Please cite this publication as follows:

Ende, S. S. W., Schrama, J. W., \& Verreth, J. A. J. (2018). The influence of prey size, sediment thickness and fish size on consumption in common sole (Solea solea L.). Journal of Applied Ichthyology, 34(1), 111-116. https://doi.org/10.1111/jai.13520 


\title{
The influence of prey size, sediment thickness and fish size on consumption in common sole (Solea solea L.)
}

\author{
S. S. W. Ende ${ }^{1,2}$ (D) | J.W. Schrama ${ }^{2}$ ～J.A. J. Verreth ${ }^{2}$
}

\author{
${ }^{1}$ Wageningen Imares, Yerseke, the \\ Netherlands \\ ${ }^{2}$ Aquaculture and Fisheries \\ Group, Wageningen University, Wageningen, \\ the Netherlands

\section{Correspondence} \\ Stephan Siegfried Werner Ende, Alfred \\ Wegener Institute, Helmholtz Centre for Polar \\ and Marine Research, Bremerhaven, Germany. \\ Email: sende@awi.de
}

Funding information

Dutch Ministry of Agriculture, Nature and Food Quality; European Fisheries Funds; the province of Zeeland; Westerschelde Compensation Funds

\begin{abstract}
Summary
This study determined prey consumption in common sole as a function of prey size (0-0.5, 1-1.5, 2-2.5 and 4-5 g), sediment thickness $(20 \mathrm{~cm}$ and $2 \mathrm{~cm})$ and fish size (50 g, $125 \mathrm{~g}$ or $300 \mathrm{~g}$ ). Prey consumption (in numbers of prey eaten per fish per day) was reduced with increasing prey size and sediment thickness, and was increased with increasing fish size ( $p<.001$ for all factors). All 3 factors showed significant two way interactions $(p<.001)$ when expressed in numbers of prey eaten. Prey consumption decreased with prey size when prey could not escape by burying $(2 \mathrm{~cm}$ of sediment thickness) irrespective of fish size. We suggest that increasing effort to ingest and handle larger prey played a role. Prey consumption increased with fish size when prey could not bury ( $2 \mathrm{~cm}$ of sediment thickness). However, when prey was able to bury (at $20 \mathrm{~cm}$ sediment thickness) prey consumption was similar irrespective of fish size $(p<.001$ for interaction fish size $\times$ sediment). This interaction suggests that with increasing fish size there is an increasing mismatch between foraging adaptation and prey burial depth. This may explain the dominance of crustaceans in the diet of adult common sole in nature, despite the high abundance of polychaetes.
\end{abstract}

\section{1 | INTRODUCTION}

Prey selection in fishes is often not an active choice of the fish but simply related to the relative vulnerability of the food items (Ivlev, 1962; Menge, 1974; Ware, 1972, 1973). One major factor influencing vulnerability of a prey is its size. Prey size vulnerability curves, i.e. numbers of prey consumed as a function of prey size, are usually dome shaped (Bailey \& Houde, 1989; Lundvall, Svanbäck, Persson, \& Byström, 1999; Manderson, Phelan, Bejda, Stehlik, \& Stoner, 1999; Manderson, Phelan, Stoner, \& Hilbert, 2000; Pastorok, 1981; Rice, Crowder, \& Rose, 1993). The decrease in number of large prey eaten when approaching the upper prey size limit is related to increasing difficulties of capturing, ingesting and handling prey (Anderson, 1988; Sissenwine, 1984; Sogard, 1997). The decrease in number of small prey eaten when approaching the lower prey size limit on the other hand is explained by increasing difficulties to detect and retain small prey (Breck \& Gitter, 1983; Howick \& O’brien, 1983; Persson, 1987).

Prey selection also depends on the ability of the fish to adapt its foraging behavior to the escape strategies of the prey. Prey use structures such as sediment or vegetation to minimize the risk of predation (Persson \& Eklov, 1995; Turner \& Mittelbach, 1990). For example, the proportion of Eurasian perch (Perca fluviatilis) young of the year that was successfully attacked by Eurasian perch was about $70 \%$ lower in tanks where refuge (vegetation) was available compared to the success rate in tanks without refuge available (Lundvall et al., 1999). Though prey of the most vulnerable size may be highly abundant, it may not be selected due to efficient escape strategies. Therefore, when conducting experimental studies on prey vulnerability as a function of size, prey's anti-predator strategies must also be considered.

Common sole (Solea solea L.) feeds on benthic invertebrates such as polychaetes, bivalves and crustaceans (Braber \& De Groot, 1973a,b; Cabral \& Costa, 1999; De Groot, 1971; Molinero \& Flos, 1991, 1992). Feeding grounds of common sole are often dominated by ragworm (polychaetes) species such as Hediste diversicolor (Müller, 1776) or Alitta virens (Sars) (formerly known as Nereis virens (Sars) (Cabral \& Costa, 1999; Heip \& Herman, 1979). The feeding behavior of common sole however seems not well adapted to the anti- predator defenses 
used by these species. Common sole exhibits a slow moving search behavior and locates prey by olfactory and tactile cues (Appelbaum, Adron, George, Mackie, \& Pirie, 1983; Appelbaum \& Schemmel, 1983; De Groot, 1969). Prey recognition by tactile cues requires physical contact with the prey. Physical contact is possible with immobile or slow moving prey. Species such as $A$. virens rapidly however retreat into their burrows when sensing predation risk. Even small individuals of $A$. virens or $N$. diversicolor are commonly found at depth of more than $5 \mathrm{~cm}$ (Caron, Desrosiers, Miron, \& Retière, 1996; Esselink \& Zwarts, 1989), a depth which is considered a safe refuge from most benthic fish (Esselink \& Zwarts, 1989). No studies have been conducted so far on the abilities of common sole to forage on buried polychaetes. The present study examines the influence of prey size, sediment thickness and fish size on prey consumption in common sole.

\section{2 | MATERIALS AND METHODS}

Common sole were obtained from a commercial fish farm (Solea BV, IJmuiden, Netherlands). The benthic polychaete, A. virens (subsequently referred to as 'prey') was used as prey and was obtained from a commercial producer (Topsy Baits, Wilhelminadorp, Netherlands). Experiments were conducted at the research facilities of Wageningen Imares in Yerseke, the Netherlands. This experiment did not need approval by the Ethical Committee for Animal Experiments as no animals were sacrificed or suffered stress during the study.

\section{1 | General experimental conditions}

We conducted two consecutive experiments using the same experimental setup. This system consisted of 18 square plastic tanks $\left(1 \mathrm{~m}^{2}\right.$ bottom area and a total water volume $300 \mathrm{~L}$ per tank) connected to a recirculation system equipped with a beadfilter. Outflow pipes were covered with screens to prevent prey from escaping experimental tanks. Seven days prior to the experimental period tanks were filled with pre-washed Metsel sand (De Houtkaai, zand en grindhandel, The Netherlands) to a depth of $20 \mathrm{~cm}$ (Experiment 1) or $20 \mathrm{~cm}$ and $2 \mathrm{~cm}$ (Experiment 2). Four prey sizes were used (0-0.5, 1-1.5, 2-2.5 and 4-4.5 g). Conditions were kept constant throughout the experimental periods (photoperiod 12L:12D; water flow- 5-6 L/ min; $\mathrm{T}-21.0 \pm 1.2^{\circ} \mathrm{C}$; salinity at $29.5 \pm 3.0$; total ammonia nitrogen $\left(\right.$ TAN) $<0.73 \mathrm{mg} / \mathrm{L}$; nitrite nitrogen $\left(\mathrm{NO}_{2}-\mathrm{N}\right)<0.55 \mathrm{mg} / \mathrm{L}$ and nitrate nitrogen $\left(\mathrm{NO}_{3}-\mathrm{N}\right)<5.5 \mathrm{mg} / \mathrm{L}, \mathrm{pH}>7.03$ ). Oxygen (DO) was kept above $>7.0 \mathrm{mg} / \mathrm{L}$ except for 1 day were DO was $3.42 \mathrm{mg} / \mathrm{L}$ due to a power failure.

\section{2 | Experiment 1}

Experiment 1 was designed to determine the inflection point, i.e. the time point after which no further increase in prey depth occurred. This time point was used in the subsequent main experiment as the latency time between introduction of prey and introduction of common sole to the tanks. In other words, prey was stocked and was allowed to bury for the given time until their deepest possible burying depth/retrieval depth was reached. At this time common sole were introduced and the experimental feeding period of 48 -h started. The second aim of Experiment 1 was to determine if prey burial depth increased with increasing prey size. The relation of prey size and prey burial depth was used for interpretation of results from Experiment 2. All tanks in Experiment 1 were filled with $20 \mathrm{~cm}$ of sediment. We considered $20 \mathrm{~cm}$ of sediment sufficient depth to perform natural burying behaviour.

Each tank $(n=18)$ was divided into 4 compartments by plastic boards giving a total of 72 experimental units (bottom area of $0.25 \mathrm{~m}^{2}$ ). By dividing tanks into smaller compartments two compartments were available per prey size and time. Each compartment was then stocked with a single prey size at a density of $1.5 \mathrm{~kg} / \mathrm{m}^{2}$. Prey were placed on top of the sediment layer. Two core samples $(7.5 \mathrm{~cm}$ diameter) were taken per compartment at a random place. Core samples were taken at $8,16,32,40,56,64,72,80,88,96,104,112$ and $120 \mathrm{hr}$ after introduction of prey. Areas bordering walls were excluded from sampling. The core sampler was forced into the sediment until the tank bottom was reached. A plug was inserted from above and the core sampler was removed. After removal the sediment sample was pushed out of the core from below into an extension and sliced into $4 \mathrm{~cm}$ pieces to get core samples of $0-4,4-8,8-12,12-16$ and $16-20 \mathrm{~cm}$. Each sample was sieved on a $0.1 \mathrm{~cm}$ sieve. Prey recovered for each sample was weighed individually to the nearest of $0.01 \mathrm{~g}$. When disturbed at or near the surface, ragworms retreat rapidly to the bottom of its burrow (Vader, 1964). Therefore, we assume that prey was recovered at the deepest burial depth.

\section{3 | Experiment 2}

In Experiment 2 we examined prey consumption as a function of prey size, sediment thickness and fish size. The influence of prey size on common sole predation was studied using a thin sediment layer of $2 \mathrm{~cm}$. A minimum of sediment was necessary because common sole struggled to catch the prey on a plastic tank floor when no sediment was available (pers. Obs.). We used only $2 \mathrm{~cm}$ of sediment to avoid that capture effort by the fish would be influenced by other factors than prey size. The influence of capture effort related to prey depth was studied using $20 \mathrm{~cm}$ of sediment thickness. We considered $20 \mathrm{~cm}$ of sediment sufficient depth to perform natural burying behaviour.

Prior to starting Experiment 2, common sole were adapted for 21 -days to the present prey type either restricted in burying $(2 \mathrm{~cm}$ sediment thickness) or unrestricted in burying $(20 \mathrm{~cm}$ sediment thickness). This adaptation was necessary as fish were exclusively fed pelleted feed before. Fish were adapted in a separate system (not the experimental system) consisting of 2 shallow raceways and 6 square plastic tanks connected to a recirculation system equipped with a drumfilter, trickling filter, ozone and UV. Conditions, i.e. sediment type, sediment depth, sediment settling time and water quality were the same as in the experimental system. During this adaptation period, prey of unsorted size were used. As a result, all common sole had access to all possible prey sizes. During the adaptation period, 
prey densities declined due to consumption. To maintain a theoretical density of $1.5 \mathrm{~kg} / \mathrm{m}^{2}$, prey was re-stocked once a week, always during daytime. No feeding activity of common sole was observed in response to newly introduced prey. This was important as active feeding on unburied prey would have interfered with the desired adaptation of common sole to forage on buried prey.

In Experiment 2, a $4 \times 2 \times 3$ factorial design was used including the following factors and levels; prey size (mean initial body weight $\pm S D$ was $0.7 \pm 0.2 \mathrm{~g}, 1.5 \pm 0.2 \mathrm{~g}, 2.4 \pm 0.2 \mathrm{~g}$ and $4.1 \pm 0.3 \mathrm{~g}$ ), sediment thickness $(20 \mathrm{~cm}$ and $2 \mathrm{~cm}$ ) and fish size (mean initial body weight $\pm S D$ of the three fish size classes was $51.8 \pm 4.2 \mathrm{~g}$, $125.8 \pm 8.8 \mathrm{~g}$ and $300.9 \pm 20.9 \mathrm{~g}$ ). Prey size classes were based on availability of prey rather than based on existing limited knowledge of prey size preferences. Each treatment was done in duplicate. It was not possible to study all treatment combinations at once. Therefore, the experiment was conducted in three series, starting with small sole, followed by medium and large soles. Prey was stocked at densities of $0.2 \mathrm{~kg} / \mathrm{m}^{2}$ with one size class per tank. An additional 100 prey individuals were weighed to determine the mean initial body weight. Results from Experiment 1 (conducted prior to Experiment 2) showed that the inflection point, i.e. time point after which no further increase in prey depth occurred, did not vary between prey size classes and varied from 15 to $23 \mathrm{hr}$. Therefore we stocked prey $24 \mathrm{hr}$ before introducing common sole. Common sole of one size class were individually weighed and introduced to the tanks at densities of 4 fish per tank. Common sole were starved for 24-h before being introduced to their respective tanks. The feeding period lasted for 48-h after which common sole were removed. Remaining prey was recovered from the sediment by sucking water, sediment and prey out of the tanks and separating prey by running the homogenate through a rotating drum. Prey was counted, and total biomass and individual weight of 100 individuals was recorded.

\subsection{Calculations and statistical analysis}

A non-linear model was applied to estimate beta (slope of first linear part), the inflection point (first time point in hours at which no further increase in depth in $\mathrm{cm}$ takes place) and the plateau (slope of second linear part assumed to be 0 ) according to the equation depth = plateau $-\log (1+\exp ($ beta $\times($ inflextion - time $)))$ The initial estimates (PARMS statement) were plateau $=8(\mathrm{~cm})$, beta $=1$ (slope) inflection $=40$ (hours). Consumption in grams of prey per fish per day was calculated as (IBM - FBM - Mprey) $\div(n \times d)$, where IBM is the prey initial biomass, FBM is the prey final biomass, Mprey is prey mortality, $d$ is the number of experimental days and $n$ is the number of fish per tank. Consumption in numbers of prey per fish per day was calculated by dividing consumption in grams of prey per fish per day by average prey weight.

Data were analysed using the Statistical Analysis Systems statistical software package version 9.2 (SAS Institute, Inc., Cary, NC, USA). For determination of the inflection point (Experiment 1) a non-linear regression (SAS 9.1) was applied based on the mean depth frequency distribution of number of worm over time. Prey size as a function of prey depth data were analysed with a one-way analysis of variance (ANOVA). Data from Experiment 2 were subjected to a three-way analysis of variance (ANOVA). In all tests the general linear model (GLM) procedure was used, followed by multiple comparisons of means using Tukey's multiple range test. In all tests, the statistical significant difference between groups were considered when $p<.05$.

\section{3 | RESULTS}

\section{1 | Experiment 1}

The non- linear model estimated the inflection point (first point at which no further increase in depth takes place) was reached at $19.6 \mathrm{hr}$ (0-0.5 g worm), at $22.5 \mathrm{hr}$ (1-1.5 g worm) and at $16.8 \mathrm{hr}(2-2.5 \mathrm{~g}$ worm). Mean prey burial depth after inflection between 24 and $112 \mathrm{hr}$ after stocking increased with increasing prey size as shown in Figure 1. The equation for the observed linear regression was $y$ (depth $)=1.78 \times($ worm size $)+6.40, R^{2}=.95 ; p<.001$, Figure 1$)$. Prey depth (mean $\pm \mathrm{SEM}$ ) ranged from $7.7 \mathrm{~cm} \pm 0.34$ (prey of $0-0.5 \mathrm{~g}$ ) to $13.3 \mathrm{~cm} \pm 0.34$ (prey of $4-5 \mathrm{~g}$ ).

\section{$3.2 \mid$ Experiment 2}

The three-way interaction of sediment thickness, fish size and prey size was significant for numbers of prey eaten $(p<.01)$, but not for grams of prey eaten $(p=.39)$. All 2 Way interactions were significant for numbers of prey eaten (Figure 2a, $c$ and e), whereas only the interaction of sediment thickness with fish size was significant in grams of prey eaten (Figure 2f). All main effects were significant both in numbers and grams of prey eaten.

Prey consumption decreased with prey size (Figure 2a, b); however an interaction between sediment thickness and prey size was observed for the numbers of prey eaten (Figure 2a). This interaction was related to a less pronounced decrease in prey consumption with sediment thickness for the largest prey size.

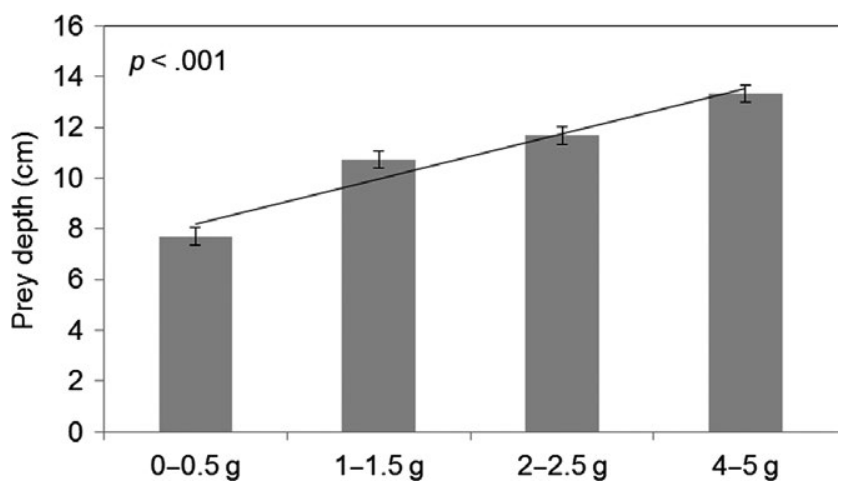

FIGURE 1 The relationship of prey size (in $g, x$ - axis) to prey depth (in cm, $y$ - axis) after 24-112 hr (after which no further increase in burial depth was measured). Error bars show the standard error of means (SEM). The equation for the observed linear regression was $y$ $($ depth $)=1.78 \times($ worm size $\left.)+6.40, R^{2}=.95 ; p<.001\right)$ 

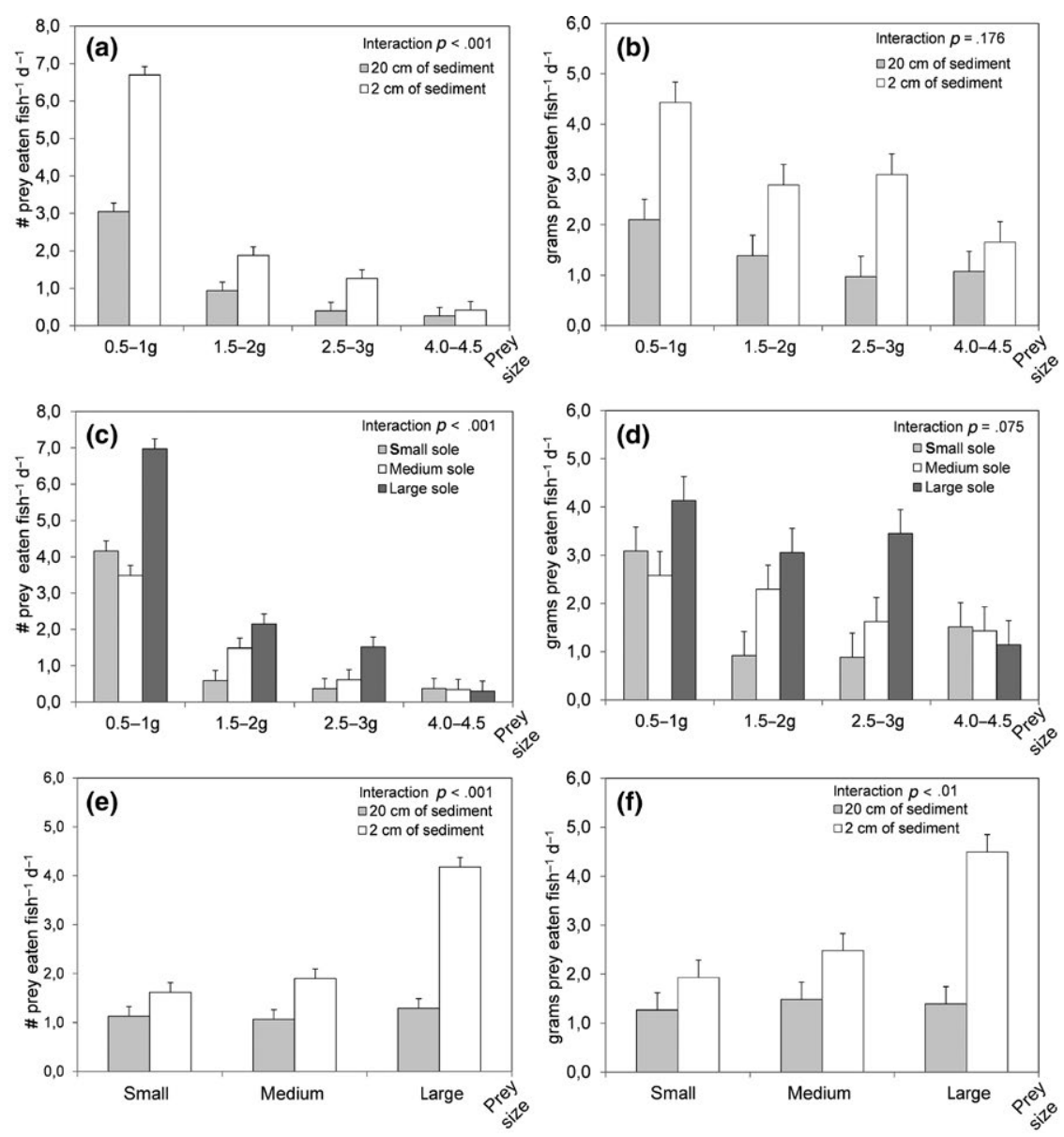

FIGURE 2 The effect of prey size $\times$ sediment thickness (a), prey size $x$ fish size (c) and sediment thickness $\times$ fish size (e) on numbers of prey eaten (prey per fish per day). The effect of prey size $\times$ sediment thickness (b), prey size $\times$ fish size (d) and sediment thickness $\times$ fish size $(f)$ on grams of prey eaten (prey per fish per day). The $x$ - axis in Figure a-d shows prey size. The $x$ - axis in Figure $e-f$ shows fish size. The $y$ - axis in Figure a, $c$ and e shows the numbers of prey eaten per fish per day. The $y$ - axis in Figure $b, d$ and $f$ shows the grams of prey eaten per fish per day. Values are least square means of duplicate tanks. Error bars show the standard error of means (SEM)
Prey consumption increased with fish size (Figure 2c, d); an interaction between prey size and fish size was present for the numbers of prey eaten (Figure 2c). This interaction was caused by the fact that prey consumption increased with fish size for small and medium sized prey but not for largest prey.

Prey consumption (both in grams and number) was influenced by an interaction between fish size with sediment thickness (Figure 2e, f). Prey consumption increased with fish size when prey could not escape by burying (in tanks with $2 \mathrm{~cm}$ of sediment). When prey was able to escape by burying, i.e. in tanks filled with $20 \mathrm{~cm}$ of sediment consumption was similar irrespective of fish size.

\section{4 | DISCUSSION}

Our results showed that prey consumption clearly decreased with prey size when prey could not escape by burying (i.e. in tanks filled with $2 \mathrm{~cm}$ of sediment) irrespective of fish size (Figure $2 \mathrm{a}-\mathrm{d}$ ). We assume that the observed relation of prey consumption and prey size in $2 \mathrm{~cm}$ is only influenced by handling and ingestion effort (see Section 2 for details). A reduction in prey consumption with increasing prey size can occur when satiation is reached with fewer prey of larger size (Gill \& Hart, 1994; Hambright, 1991; Hart \& Connellan, 1984; Hart \& Gill, 1992; Hart \& Hamrin, 1988). The observed decline also in grams of prey eaten (in addition to decline in numbers of prey eaten) with increasing prey size (Figure 2b) however suggests that satiation was not the explanation for the observed reduction in consumption in the present study. A reduction in prey consumption with increasing prey size is commonly associated with increasing efforts to capture, ingest and handle prey approaching upper prey size limits (Anderson, 1988; Sissenwine, 1984; Sogard, 1997). The observed decline in prey consumption with increasing prey size for all size classes of common sole suggests that all size classes of common sole approached upper prey size limits. This assumption is supported by the predator-prey mass ratio's (PPMR) obtained for a related tongue sole (Cynoglossus sp.), showing a similar diet specialization. The PPMR reflects the order of magnitude by which a fish is larger than its common prey. Prey above this ratio is not selected due to increasing handling and ingestion effort. The PPMR for Cynoglossus sp. is about 3.1 (Kondoh, 2011). Applying this ratio to present common sole size classes would result in considerably smaller preferred prey sizes of approximately 0.04, 0.1 and $0.24 \mathrm{~g}$ for small, medium and large common sole respectively.

Prey consumption was reduced when prey could escape by burying (i.e. in tanks with $20 \mathrm{~cm}$ of sediment), irrespective of prey size (Figure 2a) and fish size (Figure 2e). However, the highest numerical reduction was not observed for the deepest prey but for prey found at the lowest depth as can be seen by the interaction between prey size and sediment thickness. On average, consumption of the smallest prey found at the lowest depth was reduced by 3.6 individuals, whereas consumption of large prey was only reduced by 0.2 individuals. This 
suggests high capture effort for smallest prey size. Though smallest prey were found at lower depth than preceding prey size classes, they were not located within the first few centimeters of sediment. Common sole is a benthic feeder and known to rely mainly on olfactory and tactile cues to search and detect prey (Appelbaum \& Schemmel, 1983; Appelbaum et al., 1983). In addition common sole pushes its head down on to the substratum prior to each attack probably recognising a prey item (Holmes \& Gibson, 1983). This behaviour was also observed in the present study and may be used to fluidize the top sediment layer and reach shallow buried prey. However, olfactory, tactile cues and/or palpation may be foraging strategies not adapted for prey which bury in excess of the first few centimetres (Geluso, 2005; Reichman \& Oberstein, 1977).

We would have expected that capture efforts further increase with increasing burial depth. The absence of such an effect may partly be related to the fact that consumption of large prey was already limited by the low numbers of prey eaten (on average only 0.4 individuals) in tanks filled with $2 \mathrm{~cm}$ of sediment (prey size effect). Also sediment characteristics may have played a role by limiting large prey to escape predation. In the present study large $N$. virens were mainly found within the depth range of $12-14 \mathrm{~cm}$ (Figure 1), whereas in nature larger $N$. virens $(>1 \mathrm{~g}$ ) are found in excess of this depth (Caron et al., 1996). The lower depth relative to $N$. virens burying potential may be related to prey not being able to stabilize deeper burrows in the coarse sediment which we used.

Largest common sole ate the highest numbers of prey when prey could not escape by burying (e.g. in tanks with $2 \mathrm{~cm}$ of sediment). In tanks filled with $20 \mathrm{~cm}$ of sediment, i.e. when prey was able to escape by burying, similar numbers of prey were eaten irrespective of fish size, which is shown by the significant interaction (Figure 2e, f). This finding appears not in line with the major ecological concept that foraging abilities improve with fish size (Chattopadhyay \& Baumiller, 2009). The interaction of fish size $x$ sediment thickness found in the present study suggests that with fish size there is an increasing mismatch between foraging adaptation and the prey burial depth. As a consequence, in our study, larger common sole could possibly not benefit from better foraging abilities.

In conclusion, the observed reduction of prey consumption with increasing sediment thickness (i.e. prey burial depth) suggests that the foraging behaviour of common sole is less well adapted to this prey type. This poor adaptation particularly affects large common sole which were not able to consume high numbers of buried prey. Present results may explain why in nature common sole progressively substitute polychaetes by crustaceans as they grow.

\section{ACKNOWLEDGEMENTS}

We thank the personnel of the experimental facility in Yerseke (Imares) for their assistance in conducting the experiment. This study was financially supported by Dutch Ministry of Agriculture, Nature and Food Quality, the European Fisheries Funds, the province of Zeeland and the Westerschelde Compensation Funds. The funders had no role in the study design, data collection and analysis, decision to publish, or preparation of manuscript.

\section{ORCID}

\section{S. S. W. Ende (iD http://orcid.org/0000-0002-7558-7462}

\section{REFERENCES}

Anderson, J. T. (1988). A review of size dependent survival during prerecruit stages of fishes in relation to recruitment. Journal of Northwest Atlantic Fishery Science, 8, 55-66.

Appelbaum, S., Adron, J. W., George, S. G., Mackie, A. M., \& Pirie, B. J. S. (1983). On the development of the olfactory and the gustatory organs of the Dover Sole, Solea-Solea, during metamorphosis. Journal of the Marine Biological Association of the United Kingdom, 63, 97-108.

Appelbaum, S., \& Schemmel, C. (1983). Dermal sense organs and their significance in the feeding behavior of the common sole Solea Vulgaris. Marine Ecology Progress Series, 13, 29-36.

Bailey, K., \& Houde, E. (1989). Predation on eggs and larvae of marine fishes and the recruitment problem. Advances in Marine Biology, 25, 1-83.

Braber, L., \& De Groot, S. J. (1973a). The food of five flatfish species (Pleuronectiformes) in the southern North Sea. Netherlands Journal of Sea Research, 6, 163-172.

Braber, L., \& De Groot, S. J. (1973b). On the morphology of alimentary tract of flatfishes (Pleuronectiformes). Journal of Fish Biology, 5, 147-153.

Breck, J. E., \& Gitter, M. J. (1983). Effect of fish size on the reactive distance of Bluegill (Lepomis macrochirus) Sunfish. Canadian Journal of Fisheries and Aquatic Sciences, 40, 162-167.

Cabral, H., \& Costa, M. J. (1999). Differential use of nursery areas within the Tagus Estuary by sympatric soles, Solea solea and Solea senegalensis. Environmental Biology of Fishes, 56, 389-397.

Caron, A., Desrosiers, G., Miron, G., \& Retière, C. (1996). Comparison of spatial overlap between the polychaetes Nereis virens and Nephtys caeca in two intertidal estuarine environments. Marine Biology, 124, 537-550.

Chattopadhyay, D., \& Baumiller, T. K. (2009). An experimental assessment of feeding rates of the Muricid Gastropod Nucella lamellosa and its effect on a cost-benefit analysis. Journal of Shellfish Research, 28, 883-889

De Groot, S. J. (1969). Digestive system and sensorial factors in relation to the feeding behaviour of flatfish (Pleuronectiformes). Journal du Conseil, 32, 385-394.

De Groot, S. J. (1971). On the interrelationships between morphology of the alimentary tract, food and feeding behaviour in flatfishes (pisces: pleuronectiformes). Netherlands Journal of Sea Research, 5, 121-196.

Esselink, P., \& Zwarts, L. (1989). Seasonal trend in burrow depth and tidal variation in feeding activity of Nereis diversicolor. Marine Ecology Progress Series, 56, 243-254.

Geluso, K. (2005). Benefits of small-sized caches for scatter-hoarding rodents: Influence of cache size, depth, and soil moisture. Journal of Mammalogy, 86, 1186-1192.

Gill, A. B., \& Hart, P. J. (1994). Feeding behaviour and prey choice of the threespine stickleback: The interacting effects of prey size, fish size and stomach fullness. Animal Behaviour, 47, 921-932.

Hambright, K. D. (1991). Experimental analysis of prey selection by largemouth bass: Role of predator mouth width and prey body depth. Transactions of the American Fisheries Society, 120, 500-508.

Hart, P. J. B., \& Connellan, B. (1984). Cost of prey capture, growth rate and ration size in pike, Esox lucius L., as functions of prey wheight. Journal of Fish Biology, 25, 279-292.

Hart, P. J. B., \& Gill, A. B. (1992). Constraints on prey size selection by the three-spined stickleback: Energy requirements and the capacity and fullness of the gut. Journal of Fish Biology, 40, 205-218.

Hart, P., \& Hamrin, S. F. (1988). Pike as a selective predator. Effects of prey size, availability, cover and pike jaw dimensions. Oikos, 51, 220-226. 
Heip, C., \& Herman, R. (1979). Production of Nereis Diversicolor of Müller (Polychaeta) in a Shallow Brackish Water Pond. Estuarine and Coastal Marine Science, 8, 297-305.

Holmes, R. A., \& Gibson, R. N. (1983). A comparison of predatory behaviour in flatfish. Animal Behavior, 31, 1244-1255.

Howick, G. L., \& O'brien, W. J. (1983). Piscivorous feeding behavior of largemouth bass: An experimental analysis. Transactions of the American Fisheries Society, 112, 508-516.

Ivlev, V. S. (1962). Experimental ecology of the feeding of fishes. Copeia, $1,234-236$.

Kondoh, M. (2011). Scale dependence of predator-prey mass ratio: Determinants and applications. Advances in Ecological Research: The Role of Body Size in Multispecies Systems, 45, 269.

Lundvall, D., Svanbäck, R., Persson, L., \& Byström, P. (1999). Size-dependent predation in piscivores: Interactions between predator foraging and prey avoidance abilities. Canadian Journal of Fisheries and Aquatic Sciences, 56, 1285-1292.

Manderson, J. P., Phelan, B. A., Bejda, A. J., Stehlik, L. L., \& Stoner, A. W. (1999). Predation by striped searobin (Prionotus evolans, Triglidae) on young-of-the-year winter flounder (Pseudopleuronectes americanus, Walbaum): Examining prey size selection and prey choice using field observations and laboratory experiments. Journal of Experimental Marine Biology and Ecology, 242, 211-231.

Manderson, J. P., Phelan, B. A., Stoner, A. W., \& Hilbert, J. (2000). Predatorprey relations between age-1+ summer flounder (Paralichthys dentatus, Linnaeus) and age-0 winter flounder (Pseudopleuronectes americanus, Walbaum): Predator diets, prey selection, and effects of sediments and macrophytes. Journal of Experimental Marine Biology and Ecology, 251, 17-39.

Menge, J. L. (1974). Prey selection and foraging period of the predaceous rocky intertidal snail, Acanthina punctulata. Oecologia, 17, 293-316.

Molinero, A., \& Flos, R. (1991). Influence of sex and age on the feeding habits of the Common sole Solea solea. Marine Biology, 111, 493-501.

Molinero, A., \& Flos, R. (1992). Influence of season on the feeding habits of the Common sole Solea solea. Marine Biology, 113, 499-507.

Pastorok, R. A. (1981). Prey vulnerability and size selection by Chaoborus Larvae. Ecology, 62, 1311-1324.
Persson, L. (1987). The effects of resource availability and distribution on size class interactions in perch, Perca fluviatilis. Oikos, 48, 148-160.

Persson, L., \& Eklov, P. (1995). Prey refuges affecting interactions between Piscivorous Perch and Juvenile Perch and Roach. Ecology, 76, 70-81.

Reichman, O. J., \& Oberstein, D. (1977). Selection of seed distribution types by Dipodomys merriami and Perognathus amplus. Ecology, 58, 636-643.

Rice, J. A., Crowder, L. B., \& Rose, K. A. (1993). Interactions between size-structured predator and prey populations: Experimental test and model comparison. Transactions of the American Fisheries Society, 122, 481-491.

Sissenwine, M. P. (1984). Why do fish populations vary? In R. M. May (Ed.), Exploitation of marine communities (pp. 59-94). Berlin Heidelberg: Springer.

Sogard, S. M. (1997). Size-selective mortality in the juvenile stage of teleost fishes: A review. Bulletin of Marine Science, 60, 1129-1157.

Turner, A. M., \& Mittelbach, G. G. (1990). Predator avoidance and community structure: Interactions among Piscivores, Planktivores, and Plankton. Ecology, 71, 2241-2254.

Vader, W. J. M. (1964). A preliminary investigation into the reactions of the infauna of the tidal flats to tidal fluctuations in water level. Netherlands Journal of Sea Research, 2, 189-222.

Ware, D. M. (1972). Predation by rainbow trout (Salmo- airdneri): The influence of hunger, prey density, and prey size. Journal of the Fisheries Research Board of Canada, 29, 1193-000.

Ware, D. M. (1973). Risk of epibenthic prey to predation by rainbow trout (Salmo Gairdneri). Journal of the Fisheries Research Board of Canada, 30, 787-797.

How to cite this article: Ende SSW, Schrama JW, Verreth JAJ. The influence of prey size, sediment thickness and fish size on consumption in common sole (Solea solea L.). J Appl Ichthyol. 2018;34:111-116. https://doi.org/10.1111/jai.13520 